\title{
Towards the Determination of Chloride Profiles by means of Resistivity Measurements in Reinforced Concrete
}

\author{
Géraldine Villain ${ }^{1}$, Marie-Antoinette Alhajj ${ }^{1}$, Sérgio Palma Lopes ${ }^{2}$ \\ and Véronique Bouteiller ${ }^{3}$ \\ ${ }^{1}$ MAST-LAMES, Université Gustave Eiffel, IFSTTAR, Campus de Nantes, Allée des Ponts et \\ Chaussées, CS 5004, 44344 Bouguenais cedex France, geraldine.villain@univ-eiffel.fr, marie- \\ antoinette.alhajj@univ-eiffel.fr \\ ${ }^{2}$ GERS-GéoEND, Université Gustave Eiffel, IFSTTAR, Campus de Nantes, Allée des Ponts et \\ Chaussées, CS 5004, 44344 Bouguenais cedex France, sergio.palma-lopes@ univ-eiffel.fr \\ ${ }^{3}$ MAST-EMGCU, Université Gustave Eiffel, IFSTTAR, Cité Descartes, 14-20 boulevard Newton, \\ Champs sur Marne, 77447 Marne la Vallée cedex 2 France, veronique.bouteiller@univ-eiffel.fr
}

\begin{abstract}
Reinforced concrete (RC) structures, such wharfs or floating structures, are submitted to chloride ingress which can lead to rebar corrosion. Before the corrosion initiation, in a preventive point of view, engineers can be interested in non-destructive evaluation and inspection methods. In that way, electrical resistivity tomography is a promising tool to access to resistivity profiles then to chloride profiles in real $R C$ structures in the future. We would like to present herein the advances in the necessary research developments to reach this goal, i.e. the resistivity profiles obtained in reinforced concrete slabs submitted to chloride ingress. The 4 slab dimensions are $90 \times 70 \times 13 \mathrm{~cm}$. The specimens are cured, dried during 9 months then submitted to salted water imbibition during 4 months. Electrical resistivity tomography measurements are performed at short terms during 1 week of imbibition. The monitoring show that several phenomena influence the resistivity profiles such as the penetration of water and chloride ions. Meanwhile, steel rebar effect can be considered thus eliminated from electrical resistivity profiles following the method developed by (Alhajj et al. 2019).
\end{abstract}

Keywords: Electrical Resistivity Tomography, NDT, Inversion, Durability, Reinforcement.

\section{Introduction}

The preservation of our civil engineering infrastructure heritage is part of sustainable development initiatives and programs. Reinforced concrete (RC) structures exposed to de-icing salts and the marine environment may corrode through the action of chloride ions, water and oxygen. It has been shown that the methods for measuring the electrical resistivity of concrete are effective in alerting the potential corrosion risk (Gowers et al. 1999, Andrade et al. 2009). They are particularly sensitive to the moisture and chloride contents in concrete (Saleem et al. 1996). Finally, electrical resistivity tomography methods also have the great advantage of investigating the concrete from the surface to the core in a non-destructive manner and of drawing as information the apparent resistivity. However, such data need to be inverted to obtain a resistivity profile with depth (Loke et al. 1996, Chouteau et al. 2002, Fares et al. 2018). The calibration determines the conversion function to obtain the desired indicator: either the water content or the chloride content (Villain et al., Fares et al. 2018). But the presence of metal reinforcements disturbs the electric field and the measurement of apparent resistivities (Sengul 
et al. 2009, Presuel-Moreno et al. 2013, Garzon et al. 2014) and can prevent the inversion process, which is why the RILEM recommends to place itself at a distance from the reinforcements (Polder, 2001). The work of Alhajj et al. (2019) showed that it was possible to reproduce by finite elements modelling the effect of the reinforcements on the measurement of apparent resistivities.

The objective of this paper is to present the first results of the inversion programmed by Alhajj et al. (2020) for reinforced and unreinforced slabs subjected to an imbibition of a saline solution in the laboratory. The first part presents the measurement method and summarizes the inversion procedure. The second part details the experimental program. The third one shows the measurement results and the monitoring of resistivity profiles over time in both reinforced and unreinforced slabs.

\section{Method used for Non-Destructive Evaluation}

The selected non-destructive evaluation (NDE) method is electrical resistivity tomography (ERT) because it is very sensitive to the water content and chloride content of concrete.

\subsection{Electrical Resistivity Measurement Principle and Method}

The electrical resistivity method used is based on the Wenner principle for 4 electrodes regularly spaced (spacing a). The current is injected by the 2 external electrodes and the potential difference measured between the 2 inner electrodes. The apparent resistivity is calculated from current and potential measurements and a geometric cocficient G (Marescot
et al. 2006). G is calculated by finite glement modelling taking into acoount the geometry of
the test body and the position of the electrodes. If the medium is homogeneous the apparent
resistivity is equal to the «true» resistivity of the medium.
The device used was developed by (Du Plooy et al. 20 3). It consists of 14 inline electrodes, $2 \mathrm{~cm}$-spaced. This allows the implementation of 26 Wenner configurations with 4 different examined from the surface. The raw results correspond to apparent resistivities at each level of spacing. They give information about the presence of a gradient in concrete.

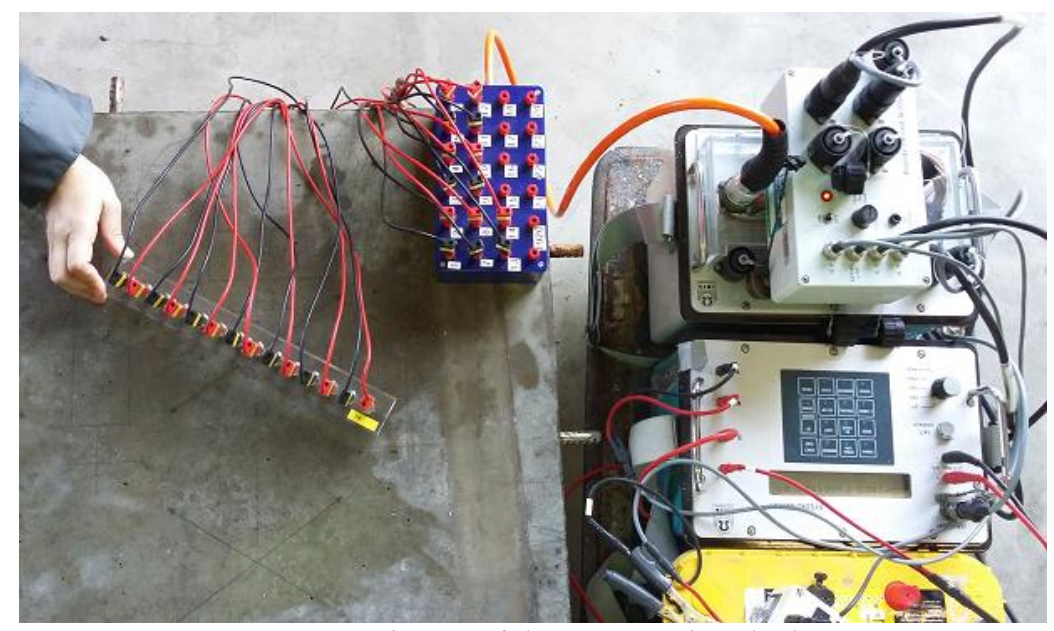

Figure 1. Picture of the ERT testing device. 


\subsection{Inversion Process}

The inversion of these raw results allows to obtain a resistivity profile according to the depth. Loke et al. (1996) notably developed an inversion algorithm for a discrete, multi-layer material model. The resulting RES1D software is free of access and gives good results for unreinforced concrete slabs. However, the presence of metal reinforcements alters the current lines in the reinforced concrete slabs, thus influencing apparent resistivity measurements. This influence can be quantified by finite element modelling (Alhajj et al. 2019). It must be taken into account in the inversion process.

An inversion process has been developed and is presented at the DBMC 2020 Congress by Alhajj et al. (2020). In summary, the imposed initial true resistivity profile is continuous and follows a Weibull law with 4 parameters. The direct finite element model (Comsol Multiphysics $\left.{ }^{\circledR}\right)$ calculates the modelled apparent resistivities. The least squares cost function between the modelled and the measured apparent resistivities is computed. A LevenbergMarquardt algorithm minimizes this cost function in order to fit an estimated resistivity profile of the concrete. The iterative optimization algorithm is written in Matlab $($ linked with Comsol and is called "IFSTTAR inversion program" in the following. The finite element model may or may not take into account steel reinforcements present or not in concrete slabs. The resistivity profile obtained corresponds to the resistivity of the concrete material with a gradient of saline solution, independently of the conductive steel influence.
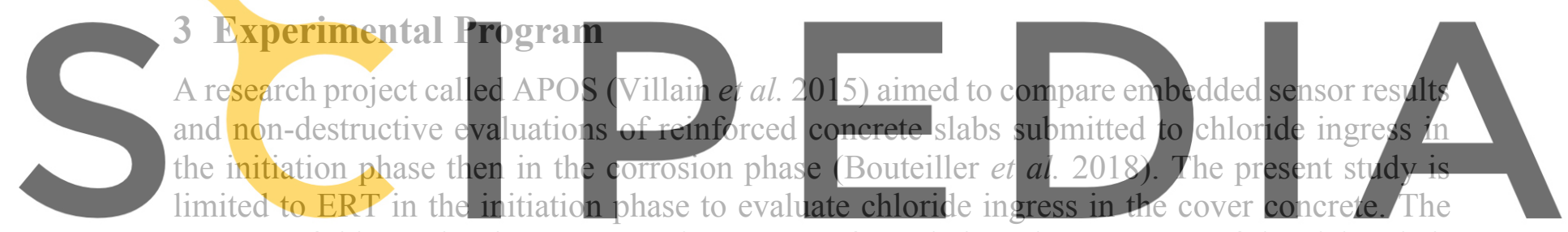

purpose of this section is to present the concrete formulation, the geometry of the slabs, their

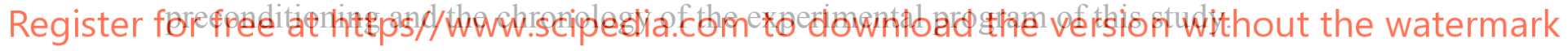

\subsection{Concrete and Slabs}

Table 1. Concrete mix design and properties.

\begin{tabular}{ccc}
\hline Aggregates 11.2/22.4 & $\left(\mathrm{kg} / \mathrm{m}^{3}\right)$ & 760 \\
\hline Aggregates 6.3/10 & $\left(\mathrm{kg} / \mathrm{m}^{3}\right)$ & 320 \\
\hline Sand 0-4 & $\left(\mathrm{kg} / \mathrm{m}^{3}\right)$ & 860 \\
\hline Cement CEM I 52.5N CE CP2 NF St Pierre La Cour & $\left(\mathrm{kg} / \mathrm{m}^{3}\right)$ & 305 \\
\hline Total water & $\left(\mathrm{kg} / \mathrm{m}^{3}\right)$ & 190 \\
\hline Admixture AD Sika Prise SC2 & $\left(\mathrm{kg} / \mathrm{m}^{3}\right)$ & 0.7 \\
\hline Water to cement ratio & $\mathrm{W}_{\mathrm{eff}} / \mathrm{C}(-)$ & 0.58 \\
\hline Compressive strength at 28 days & $\mathrm{Rcsat}(\mathrm{MPa})$ & $36.3 \pm 0.9$ \\
\hline Saturated mean density & $\rho_{\text {sat }}\left(\mathrm{kg} / \mathrm{m}^{3}\right)$ & $2332 \pm 23$ \\
\hline Porosity (water saturation under vacuum) & $\phi(\%)$ & $15.9 \pm 0.7$ \\
\hline
\end{tabular}

Concrete is of type C30 containing ordinary Portland cement (Table 1). Its 28-day compressive strength equals $36.3 \pm 0.9 \mathrm{MPa}$ and its porosity equals $15.9 \pm 0.7 \%$. For this concrete, 10 slabs 
were casted to study the penetration of a saline solution of concentration $[\mathrm{NaCl}]=35 \mathrm{~g} / \mathrm{L}$, close to that of the Atlantic Ocean. Among these slabs, we will study here 1 non-reinforced slab placed in salt solution (noted 13-NS), 2 slabs reinforced with carbon steel placed in salt solution (noted 14-CS and 15-CS), and 1 reinforced slab with stainless steels (noted 18-SS).

The dimensions of all the slabs are $90 \times 75 \times 13 \mathrm{~cm}$. The reinforced slabs contain 1 single bed of rebars placed at $3 \mathrm{~cm}$ of depth, forming 4 meshes of 20x30 cm (Figure 2).

After casting, the moulds were removed at the age of 3 days. Then, the slabs were placed in a room first not ventilated for 3 months and then ventilated with fans for 6 months to accelerate drying. The side faces are protected by 2 layers of epoxy resin to keep transfers along the depth.

a)

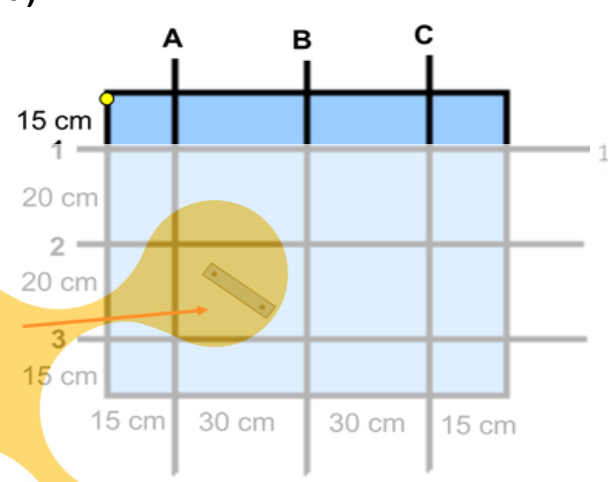

b)

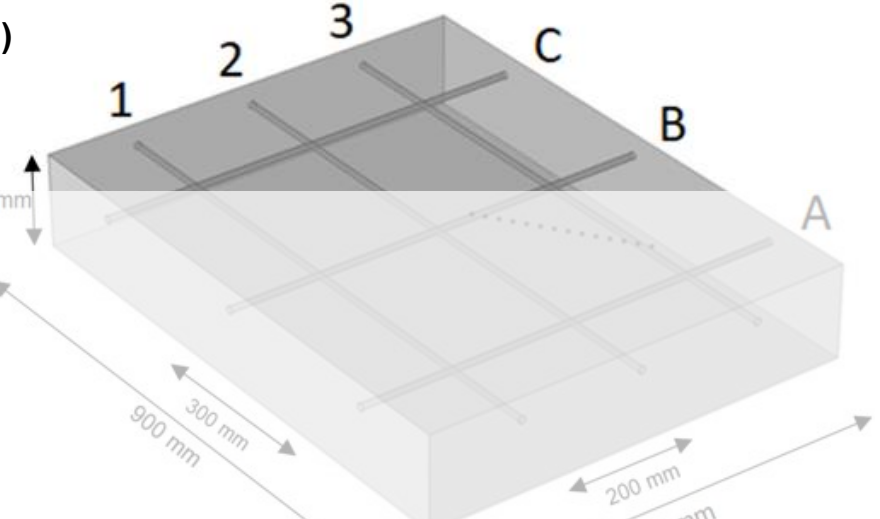

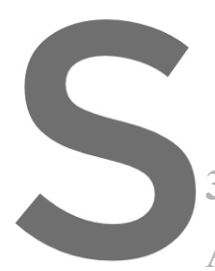

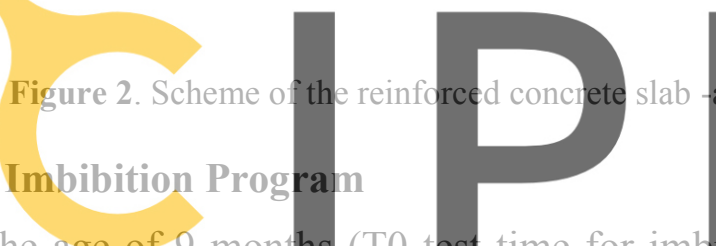

At the age of 9 months (T0 test time for imb
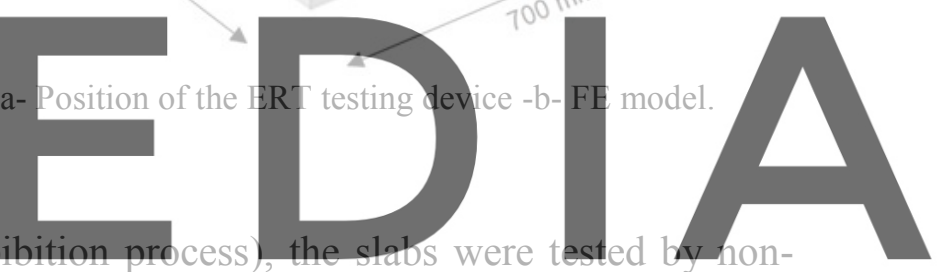

destructive evaluation methods (NDT) and then placed in 1 to $2 \mathrm{~cm}$ of salt solution in pools, so

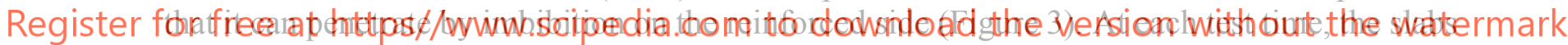
are removed from the salt solutions and subjected to NDT testing; then, they are put back in the pools. The chosen test times are about 1h, 4h, 1 day, 2 days, 7 days, 1 month, 4 months. Note that there can be differences between the slab for the out-of-water duration due to the numerous slabs and NDT methods. Here, we present the results of the first 4 test times (T1 to T4) which correspond to the imbibition of salt solution under temperature conditions of about $18-20^{\circ} \mathrm{C}$. Moreover, at these early test times, the resistivity contrasts are higher and the ERT method gives thus the best results.

For each test time, the resistivity measurements were performed on the mesh AB23 along both diagonals (Figure 2), minimum twice, usually 3 or 4 times. The mean values are used for inversion.

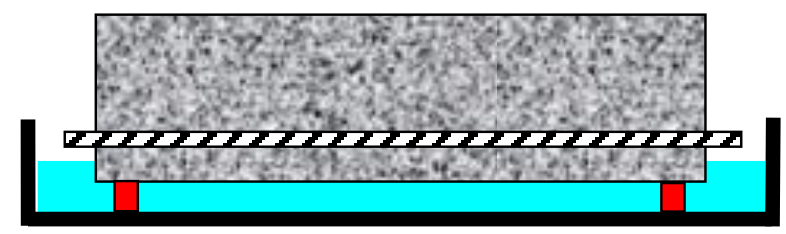

Figure 3. Scheme of the slab during the imbibition process in a pool filled with saline solution and showing the steel reinforcement. 


\section{Raw Results and Profiles of Resistivity versus Depth}

The influence of the steel reinforcement on the apparent resistivity measurements is presented, first. Then, the inverted resistivity profiles are show in the $2^{\text {nd }}$ and $3^{\text {rd }}$ sub-sections.

\subsection{Raw Results and Influence of Steel Rebars}

Figure 4 shows the apparent resistivity measurements determined for 4 spacings of the Wenner configuration, for test times $\mathrm{T} 1$ to $\mathrm{T} 4$. The resistivity measurement was impossible at $\mathrm{T} 0$ because the slab surface was too dry. In Figure 4-a, corresponding to the non-reinforced slab 13-NS, at T1, the apparent resistivity is lower near the face in contact with the salt solution $(\mathrm{a}=2 \mathrm{~cm})$ than for larger spacings corresponding to higher volumes of investigation. Moreover, for later test times, the apparent resistivity decreases due to salt solution ingress into the concrete.

In Figure 4-b, corresponding to the reinforced slab 14-CS, for small spacing $a=2 \mathrm{~cm}$, the apparent resistivity values are similar for both slabs, they decrease when the salt solution penetrates along time. But, for the other spacings, the larger are the spacings, the lower are the apparent resistivities. This is due to the steel rebar influence in accordance with literature results (Polder, 2001). This influence was quantified by a direct model using finite elements by Alhajj et al. (2019).
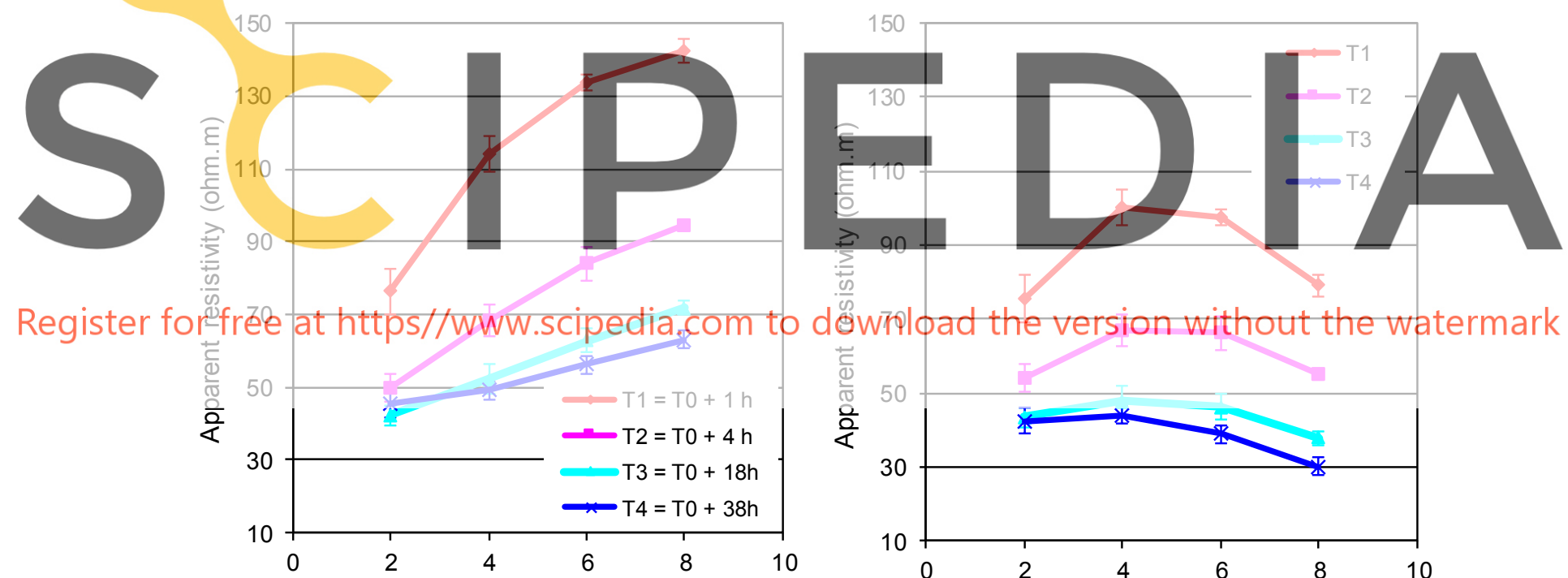

a)

Spacing $(\mathrm{cm})$

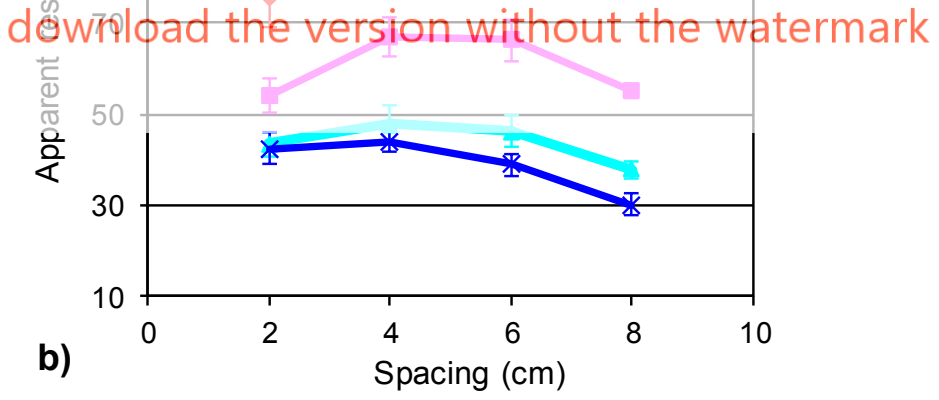

Figure 4. Apparent resistivity measurements for 4 Wenner configuration spacings -a- Unreinforced slab 13-NS b- Reinforced slab 14-CS.

\subsection{Resistivity Profiles versus Depth in the Unreinforced Concrete Slab}

For each test time, the apparent resistivities obtained for the unreinforced slab (13-NS) are inverted:

- Firstly, by using the free-access software RES1D from Loke (2001); the resulting resistivity profiles are shown in Figure 5-a;

- Secondly, by using the ISTTAR Program; the resulting resistivity profiles are shown in 
Figure 5-b and compared to the RES1D resistivity profiles.

In Figure 5, the resistivity profiles show the salt solution ingress. Concerning RES1D (Fig. $5-a)$, the inversion process is very fast. Figure 5-b presents the results of both inversion programs which are in a good agreement especially at the 2 first test times. This can be explained by the ERT method, more informative about shallower volumes, thus less accurate for deeper volumes.

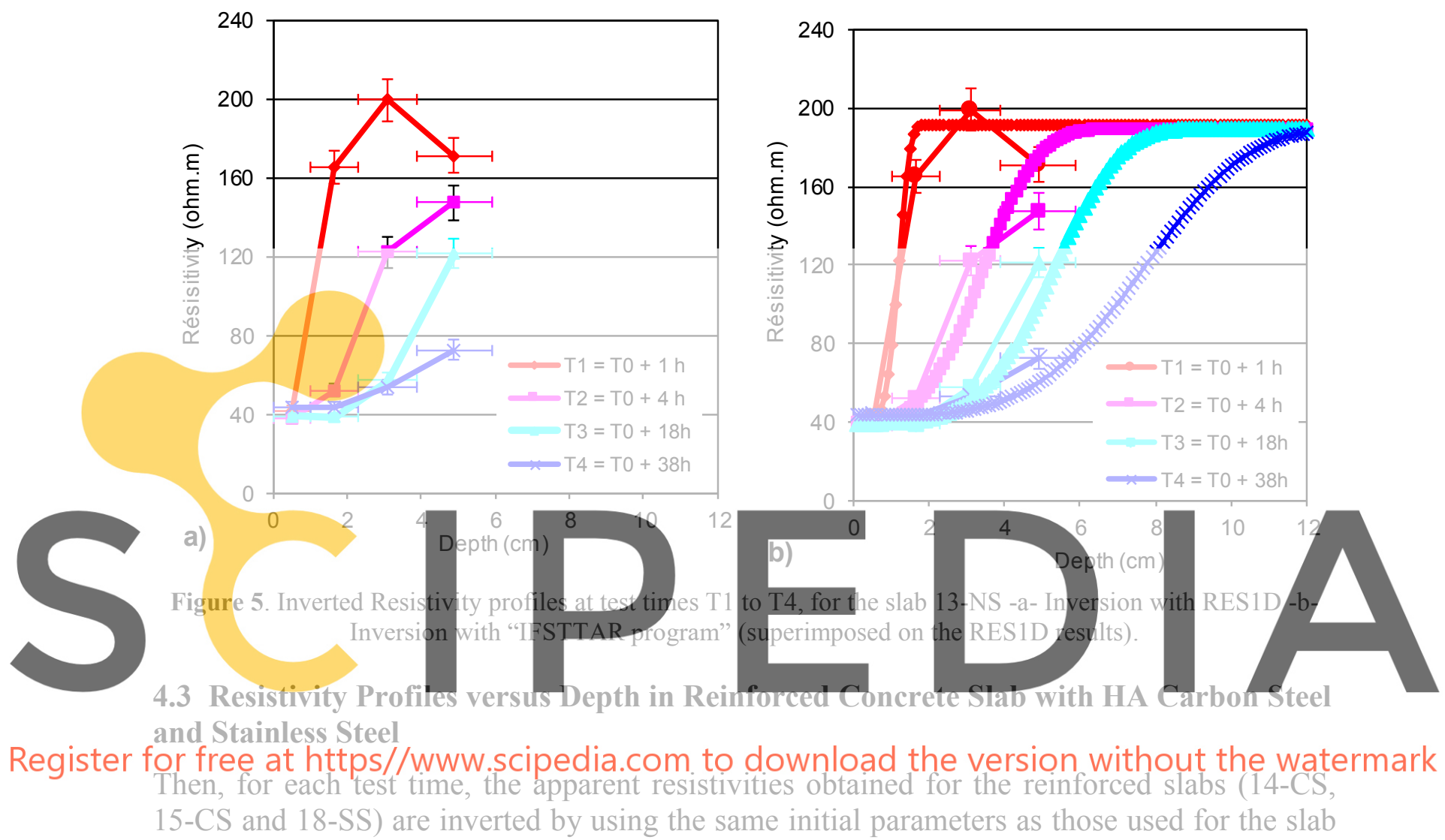

13-NS. The inversion is performed with IFSTTAR program because it is not possible with RES1D.

Figure 6-a makes it possible to compare the resistivity profile obtained for unreinforced slab (13-NS) and reinforced slab (14-CS). Figure 6-b presents the resistivity profiles obtained for the 3 reinforced slabs.

The profiles in non-reinforced and reinforced slabs are very similar for T1, T2 and T3 (Fig. 6-a). The discrepancies between the profiles are of the same order of magnitude as the ones between the profiles of the 3 reinforced slabs (Fig. 6-b). This uncertainty can be due to the concrete material variations which influence the kinetics of the penetration of the salt solution. For the later test times, the discrepancies between all the curves increase. The uncertainty of the measurement method for a higher spacing is higher.

Moreover, the resistivity profile of the slab reinforced with stainless steel rebars (18-SS) is similar to the profiles of the 2 other slabs reinforced with carbon steel rebars (14 and 15-CS). The reinforcement is indeed in passive conditions in this study. 


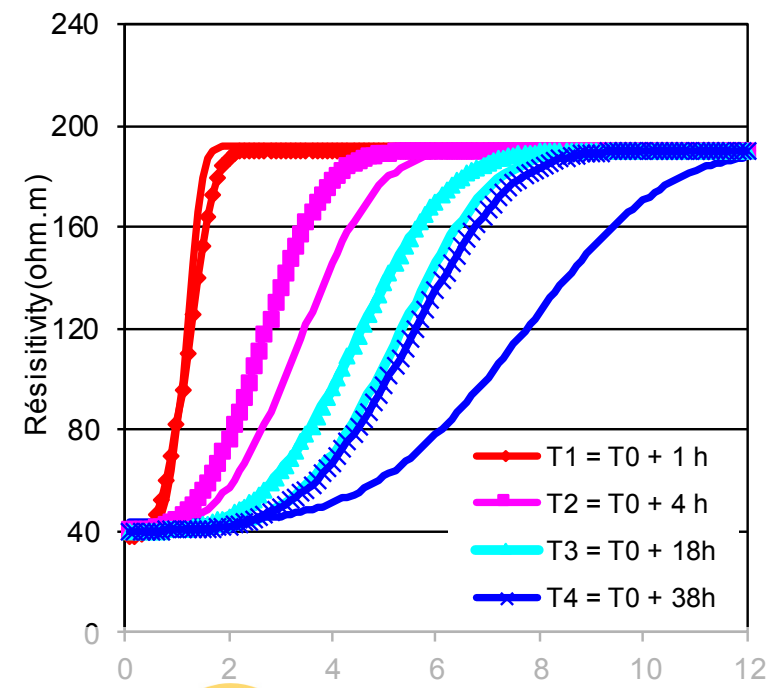

a)

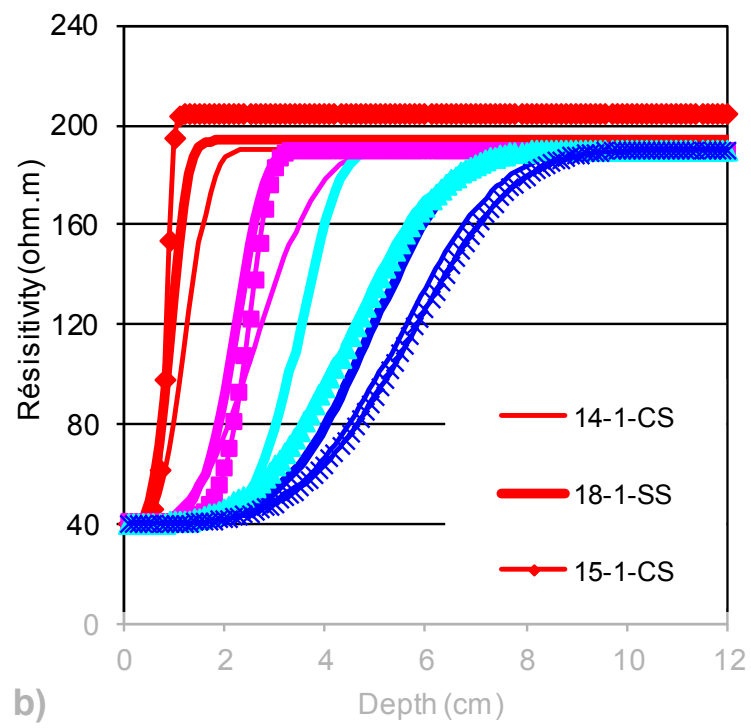

Figure 6. Comparison of resistivity profiles corresponding to salt solution ingress in non-reinforced and reinforced conerete slabs -a- Slabs 13-NS and 14-CS (line with marks) -b- Slabs 14-CS, 15-CS and 18-SS.

\section{Conclusions and Further Developments}
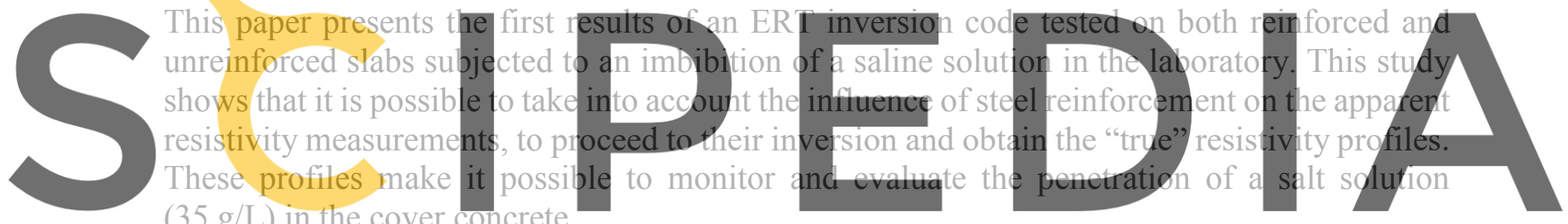

$(35 \mathrm{~g} / \mathrm{L})$ in the cover concrete.

Four slabs, either non-reinforced or reinforced with carbon or stainless steel rebars were

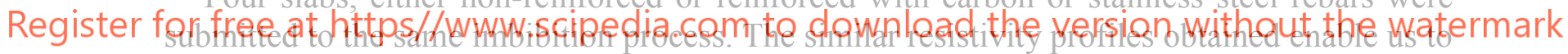

assess the uncertainty range due to both the concrete material variability and the ERT method

itself. Indeed, the ERT uncertainty increases with high value of resistivity (it is higher for the dry core of slabs) and ERT give less information for larger volumes of investigation.

Note that carbon and stainless steel give similar resistivity results in passive conditions.

However, to convert resistivity profiles into free chloride content profiles, calibration curves are needed, but they are not available at various water contents. Imbibition is a rapid process but more complex than diffusion in saturated conditions. This point has to be developed.

In further developments, non-destructive evaluations by ERT will be compared to embedded sensors in the concrete slab in view of structural health monitoring.

\section{Acknowledgements}

The authors would like to thank all the team from the Regional Laboratory of de Saint-Brieuc (Cerema) in particular B. Thauvin, R. Queguiner, S. Pasquiet, P. Boulaire for the slab instrumentation and casting, as well as the slab survey during the experimental campaign. The authors are also grateful to the Ministry of Ecology MTES, IFSTTAR and Cerema for their financial support of the research project APOS. 


\section{ORCID}

Géraldine Villain: https://orcid.org/0000-0002-4478-034X

Marie-Antoinette Alhajj: https://orcid.org/0000-0001-7711-5103

Sérgio Palma Lopes : https://orcid.org/0000-0001-7022-389X

Véronique Bouteiller: https://orcid.org/0000-0003-1467-0622

\section{References}

Alhajj M.A., Palma Lopes S. and Villain G. (2019). Accounting for steel rebar effect on resistivity profiles in view of reinforced concrete structure survey, Constr. Build. Mat., 223, 898-909. /10.1016/j.conbuildmat.2019.07.208

Alhajj M.A., Villain G., Bourguignon S. and Palma-Lopes S. (2020). A joint inversion technique of electric and electromagnetic measurements for the determination of water saturation profiles in concrete structures, In $X V$ Int. Conference on Durability of Building Materials and Components DBMC 2020, Barcelona, Spain, 6p.

Andrade C., D'Andréa R., Castillo A. and Castel M. (2009). The Use of Electrical Resistivity as NDT Method for the Specification of the durability of Reinforced Concrete. In Proceedings of the Int. Symposium on NonDestructive Testing in Civil Engineering NDTCE'09. Nantes, France, 2009.

Badr J., Fargier Y., Palma-Lopes S., Deby F., Balayssac J.P., Delepine-Lesoille S., Cottineau L.M., and Villain G. (2019). Design and Validation of a Multi-Electrode Embedded Sensor to Monitor Resistivity Profiles over Depth in Concrete, Constr. Build. Mat., 223, 310-321./10.1016/j.conbuildmat.2019.06.226

Bouteiller V., Villain G., Thauvin B., Marie-Victoire E. and Bouichou M. (2019). Evaluation de la durabilité du beton armé vis-a-vis des ions chlorure à l'aide de capteurs noyés dans le beton versus des auscultations en parement, In Proceedings of AFGC'2019, Cachan, France, 20 et 21 mars 2019, 8p.

Chouteau M. and Beaulieu S. (2002). An investigation on application of the electrical resistivity tomography method to concrete structures., In: 2nd Annu. Conf. Appl. Geophys. NDT Methodol. to Transp., 2002.

Du Plooy R., Palma Lopes S., Villain G and Dérobert X.
multi-electrode resistivity probe for investigation of
Fares M., Villain G., Bonnet S., Palın Lopes S., Thauvin
profiles in concrete using a resistivity
/10.1016/j.cemconcomp.2018.08.001
Loke M.H. and Barker R.D. (1996). Rapid least-squar
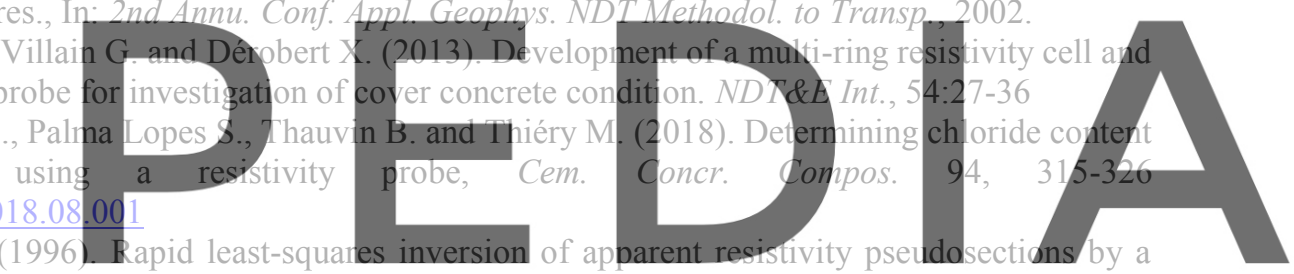

quasi-Newton method, Geophysical Prospecting, 44, 131-152./10.1111/j.1365-2478.1996.tb00142.

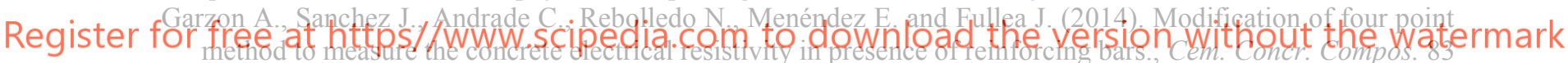
$308-322$.

Gowers K.R. and Millard S.G. (1999). Measurement of concrete resistivity for assessment of corrosion severity of steel using Wenner technique, ACI Materials Journal, 1999, 96(5)

Marescot L., Rigobert S., Palma Lopes S., Lagabrielle R. and Chapellier D. (2006). A general approach for DC apparent resistivity evaluation on arbitrarily shaped 3D structures, Journal of Applied Geophysics, 60, 55-67

Polder R.B. (2001) Test methods for on site measurement of resistivity of concrete- a RILEM TC-154 technical recommendation, Constr. Build. Mater, 2001, 15, 125-131

Presuel-Moreno F., Liu Y. and Wu Y. (2013). Numerical modeling of the effects of rebar presence and/or multilayered concrete resistivity on the apparent resistivity measured via the Wenner method., Constr. Build. Mater. 48: 16-25.

Saleem M., Shameemt M., Hussain S. and Maslehuddintf M. (1996). Effect of moisture, chloride and sulphate contamination on the electrical resistivity of Portland cement concrete., Constr. Build. Mater. 10: $209-214$.

Sengul O. and Gjorv O. (2009). Effect of embedded steel on electrical resistivity measurements on concrete structures., ACI Mater J. 106: 11-18.

Villain G., Orcesi A., Gaillet L. and Thauvin B. (Eds) (2015). Résultats des opérations de recherche APOS et $M C V$, IFSTTAR \& CEREMA, IFSTTAR, Marne-la-Vallée, 2015 Actes Interactifs, AII1. website: Site internet APOS : http://www.ifsttar.fr/collections/ActesInteractifs/AII1/index.html

Villain G., Garnier V., Sbartaï M., Dérobert X. and Balayssac J.P. (2018). Development of a calibration methodology to improve the on-site non-destructive evaluation of concrete durability indicators., Mater. Struct. 51-40. 